\title{
Identifikasi Akar Masalah Tanaman Kolesom Jawa Tidak Bernilai Ekonomi Pada Masyarakat Desa Arjasa dan Rancang Solusi
}

\author{
Diah Ayu Retnani Wulandari, Sri Hartatik*, Kacung Hariyono \\ Universitas Jember \\ e-mail: diah.retnaniw@unej.ac.id, *srihartatik.faperta@unej.ac.id, \\ kacunghariyono@yahoo.com.au
}

\begin{abstract}
ABSTRAK
Kolesom Jawa merupakan tanaman herbal yang memiliki banyak kasiat bagi Kesehatan tubuh manusia sehingga memiliki harga yang tinggi ketika telah menjadi produk siap saji. Kolesom yang bernilai tinggi menjadi tidak bernilai diantara warga di desa Arjasa dan sekitarnya, sehingga hal ini perlu diidentifikasi penyebab permasalahan itu terjadi. Kolesom Jawa ini bisa menjadi peluang usaha baru bagi ibu rumah tangga dimasa pandemic untuk memperoleh tambahan penghasilan dari nilai ekonomi olahan tanaman kolesom Jawa. Identifikasi permasalahan suatu kondisi di dalam lingkungan dapat menggunakan berbagai macam metode.untuk mengetahui akar masalahnya sehingga bisa memperoleh solusi yang tepat. Pada kegiatan ini dilakukan analisa akar masalah menggunakan root couse analysis dengan menggunakan Teknik fishbone dan teknik 5 whys. Penerepan RCA pada penelitian ini menggunakan dua teknik yaitu teknik fishbone menggunakan kategori sehingga dapat digunakan sebagai arahan kemudian 5 why diagram untuk membantu mengidentifikasi faktor penyebabnya sehingga akar masalah mengerucut. Hasil dari kegiatan ini diperoleh bahwa Identifikasi akar masalah diperoleh dari kegiatan analisis deskripsi kualitatif melalui survey wawancara kemudian dianalisis menggunakan Teknik fishbone untuk memperoleh penyebab terjadinya masalah yang dihadapi. Teknik fishbone ini sebagai arahan kemudian dilanjutkan dengan teknik 5 whys karena dapat menunjukkan hubungan kausal sebab akibat, dan mampu menggabungkan cara berpikir aksi maupun kondisi. Akar masalah yang didapat adalah kurangnya sarana dan prasarana sebagai pusat informasi pengembangan warga. Solusi yang dilakukan adalah dalam bentuk penyuluhan berupa solusi dan praktek sebagai wadah untuk meningkatkan pengetahuan warga.
\end{abstract}

Kata kunci: Kolesom Jawa, Fishbone, 5 whys

\section{ABSTRACT}

Kolesom jawa is an herbal plant so having high price when become ready-to-eat product. High value Kolesom becomes worthless among residents in Arjasa village, so need to identify the cause of the problem. It can be a new business opportunity for housewives during the pandemic. Identifying the problem of a condition in the environment can use various methods to find out the root of the problem so that it can get solution. a root cause analysis was carried out using the fishbone technique and the 5 whys technique. The implementation of RCA in this study uses two techniques, namely the fishbone technique using categories so that it can be used as a direction and then 5 why diagrams to help identify the factors causing the problem to congeal. The results of this activity showed that the identification of the root of the problem was obtained from the qualitative description analysis activity through an interview survey then analyzed using the fishbone technique to obtain the causes of the problems faced. This fishbone technique as a direction is then followed by the 5 whys technique because it can show a causal relationship of cause and effect, and is able to combine ways of thinking of actions and conditions. The root of the problem is the lack of facilities and infrastructure as a center for community development information. The solution taken in the form of counseling with sosialization and practices as a forum for increasing knowledge.

Keywords: Kolesom jawa, Fishbone, 5 whys

\section{PENDAHULUAN}

Indonesia merupakan negara agraris yang memiliki potensi sumber daya alam melimpah namun masih perlu dikembangkan khususnya di sektor pertanian secara optimal sesuai dengan kondisi, kearifan lokal dan kekhasan daerah. Di kabupaten Jember terdapat sebuah desa yang bernama desa Arjasa di kecamatan Arjasa. Desa ini memiliki luas wilayah $6,64 \mathrm{~km}^{2}$ ketinggian 141 meter dengan 5 dusun. Desa arjasa memiliki tanah produktif sebesar 664 meter yang 
digunakan untuk sawah, tegal, kebun, bangunan halaman dan lain lain. Desa Arjasa merupakan desa dengan kepadatan penduduk terbesar kedua dari seluruh desa yang ada dikecamatan Arjasa yaitu sebesar 8.409 dengan kepadatan 1.601,71 jiwa/km2 (Koordinator Statistik Kecamatan Arjasa, 2018). Masyarakat desa Arjasa sebagian besar bekerja sebagai petani. Kondisi di desa Arjasa masih memiliki lahan pertanian yang luas dan tanah yang subur serta air yang memadai sehingga tanaman mudah tumbuh subur di daerah Arjasa begitu juga dengan tumbuhan liar. Tumbuhan akan semakin subur dan rimbun pada musim penghujan seperti Gambar 1. Saat musim penghujan inilah tumbuhan kolesom Jawa semakin tumbuh subur di beberapa titik di lingkungan Arjasa, namun sayangnya penduduk di didesa Arjasa tidak banyak yang mengetahui manfaat dari tanaman tersebut sehingga hanya berakhir di pembuangan sampah. Hanya segelintir orang saja yang mengetahui manfaat tanaman tersebut.
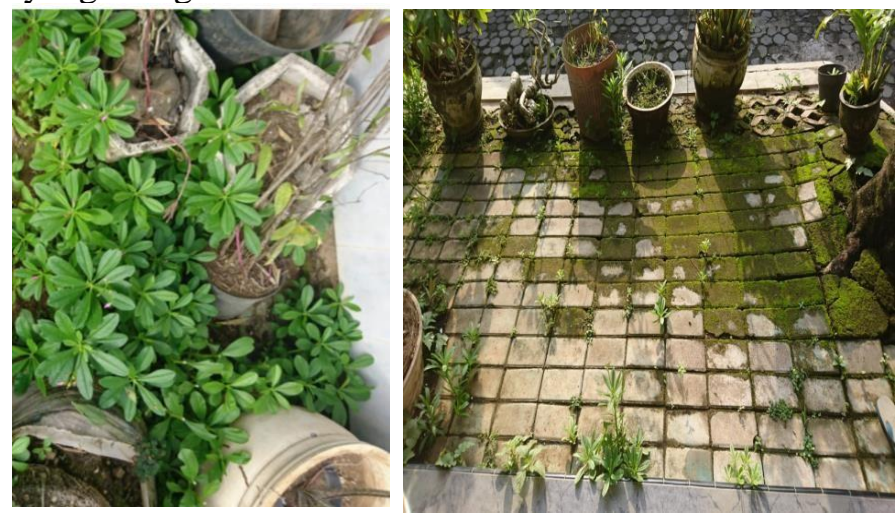

Gambar 1. kolesom tumbuh liar dihalaman rumah warga desa Arjasa

Kolesom jawa merupakan tanaman herbal yang memiliki banyak kasiat bagi Kesehatan tubuh manusia seperti akar berkhasiat untuk menguatkan paru, untuk mengurangi batuk, tonikum, diare, haid tidak teratur, keputihan dan afrodisiak. Sementara itu, daunnya berkhasiat meningkatkan nafsu makan (stomakis) melancarkan pengeluaran ASI, bisul, dan pembengkakan (anti radang) (Badrunasar. A, Santoso. H.B . 2016). Hampir Sebagian batang tubuh tanaman kolesom jawa berkhasiat. Hal ini dikarenakan tanaman tersebut memiliki berbagai macam kandungan kimia yang bermanfaat bagi tubuh manusia antara lain Kandungan Kimia yang dimiliki daun mengandung saponin, flavonoid, tanin dan steroid (Kalium 41,44 \%, Natrium 10,03 \%, Kalsium 2,21 \%, Magnesium 5,50 \% dan Besi 0,32\%) (K. Natasha, dkk. 2019).

Tanaman kolesom jawa sendiri memiliki harga yang tinggi Ketika telah menjadi produk siap saji seperti daunnya menjadi kripik, akar nya dijadikan bentuk bubuk untuk minuman siap saji, sehingga memiliki peluang bisnis yang menjanjikan selain manfaat untuk Kesehatan. Kolesom yang bernilai tinggi ditengah masyarakat menjadi tidak bernilai diantara warga didesa arjasa dan sekitarnya, sehingga hal ini perlu diobservasi untuk diidentifikasi penyebab permasalahan itu terjadi, karena kolesom jawa merupakan tanaman yang banyak ditemui di desa arjasa namun tidak bernilai bagi masyarakat desa arjasa. Kolesom jawa ini bisa menjadi peluang usaha baru bagi ibu rumah tangga dimasa pandemic ini untuk memperoleh tambahan penghasilan dari nilai ekonomi olahan tanaman kolesom jawa.

Identifikasi permasalahan suatu kondisi didalam lingkungan dapat menggunakan berbagai macam metode.untuk mengetahui akar masalahnya sehingga bisa memperoleh solusi yang tepat. Pada kegiatan ini dilakukan terlebih dahulu Analisa akar masalah menggunakan root couse analysis dengan menggunakan Teknik fishbone dan kemudian Teknik 5 whys. Penerepan RCA pada penelitian ini menggunakan dua teknik yaitu teknik fishbone menggunakan kategori sehingga dapat digunakan sebagai arahan kemudian 5 why diagram untuk membantu mengidentifikasi faktor penyebabnya hingga akar masalah mengerucut. menurut penelitian yang dilakukan oleh Tri Susanto, Djoko Pramono, Nanang Yudi Setiawan tahun 2018 dengan judul "Analisis dan Perbaikan Proses Bisnis Menggunakan Metode Business Process Improvement (BPI) (Studi Kasus: PT. Wonojati Wijoyo)" melakukan perbaikan pada salah satu divisi accounting dan menggunakan Five Whys Analysis dan Value 
Chain Analysis, Five Whys Analysis dapat digunakan untuk membantu menemukan permasalahan yang ada dan membantu tim untuk memahami lebih dalam tentang permasalahan yang dihadapi.

Analisis akar masalah penyebab tanaman kolesom jawa tidak bernilai ditengah masyarakat desa arjasa menjadi permasalahan utama pada kegiatan awal tim pengabdian untuk menentukan Langkah kegiatan pengabdian selanjutnya dalam meningkatkan nilai ekonomi kolesom jawa yang memiliki peluang berdampak pada peningkatan perekonomian warga Arjasa.

\section{BAHAN DAN METODE}

Pada kegiatan pengabdian kepada warga desa Arjasa ini memiliki beberapa kegiatan namun artikel ini akan membahas terkait Langkah awal yang dilakukan. Langkah awal yang dilakukan adalah mengidentifikasi akar masalah yang terjadi ditengah masyarakat desa Arjasa sebelum menentukan metode dan kegiatan penyelesaian yang diberikan kepada masyarakat. Kegiatan ini dilakukan pada tahun 2020, berisi Focus group discussion (FGD) untuk menggali informasi dari masyarakat desa Arjasa, dan observasi ke beberapa titik dilingkungan desa Arjasa sebagai langkah dalam perpanjangan pengamatan. Kegiatan ini bersifat deskripsi kualitatif. Penerapan identifikasi akar masalah dengan berdasarkan metode RCA yakni metode 5-Whys dan metode Fishbone Diagram atau The Cause-and-Effect Diagrams (CED). Wawancara dengan menekankan tentang 'Mengapa suatu permasalahan terjadi?' untuk mengekplorasi penyebab yang mendasari masalah hingga kesimpulan bisa tercapai. Data wawancara dalam kegiatan ini merupakan data utama yang menjadi bahan analisis untuk menjawab permasalahan. Data setelah wawancara lalu dirangkum kemudian dimasukkan ke dalam satuan-satuan untuk dikategorikan. Hasil yang diperoleh dari pengumpulan dan pengolahan data dari wawancara kemudian digambarkan dalam fishbone diagrams.

\section{HASIL DAN PEMBAHASAN}

Kolesom yang bernilai tinggi tidak bernilai diantara warga Arjasa dan sekitarnya, sehingga hal ini perlu diobservasi penyebabnya. Setelah melakukan wawancara dan observasi seperti pada Gambar 2 dan studi literatur dari laporan yang berjudul kecamatan Arjasa dalam angka tahun 2018 yang diterbitkan oleh badan pusat statistik kemudian dapat digambarkan dengan diagram fishbone penyebab kolesom tidak bernilai ekonomi di masyarakat desa Arjasa seperti pada Gambar 3.

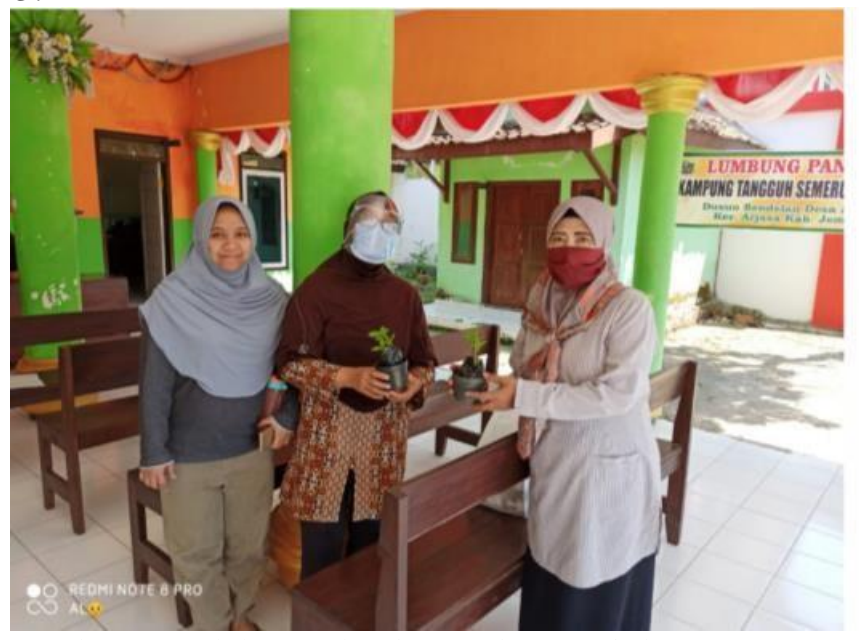

Gambar 2. Salah satu kegiatan observasi dan wawancara 


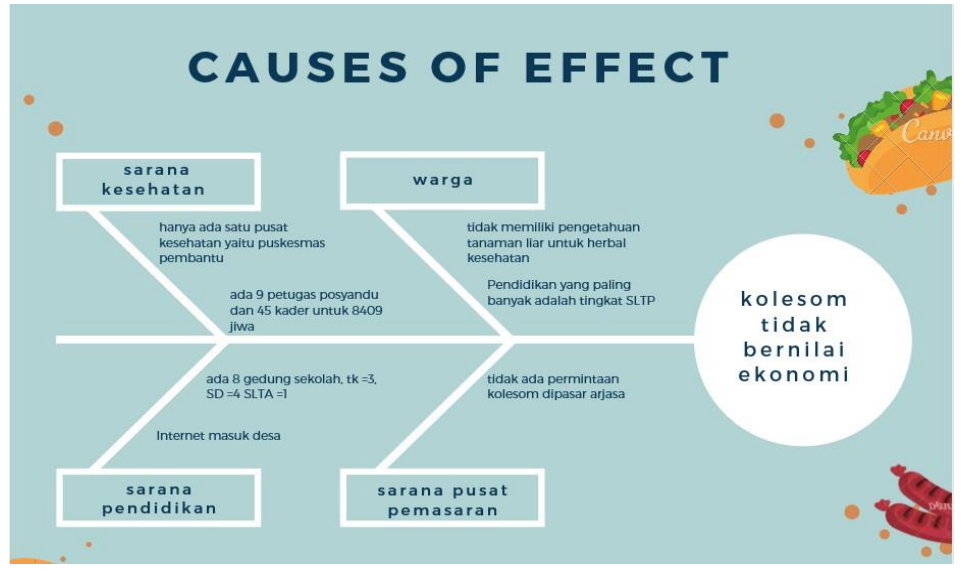

Gambar 3 . fishbone diagrams

Kolesom Jawa tidak bernilai di masyarakat desa Arjasa karena warga tidak memiliki pengetahuan bahwa tanaman liar kolesom Jawa dapat digunakan sebagai herbal yang berkhasiat bagi kesehatan. Hal ini ditunjang dari data sarana pusat kesehatan masyarakat desa sangat minim hanya ada satu puskesmas pembantu dan ditengah masyarakat hanya ada 9 petugas posyandu dan 45 kader yang tersebar untuk membantu 8.409 jiwa penduduk. Sarana kesehatan masyarakat sangat penting tidak hanya untuk melakukan check up dan perawatan kesehatan namun dapat dijadikan sumber pengetahuan tentang kesehatan yang didapat langsung dari ahlinya. Selain sarana kesehatan tempat memperoleh informasi seputar kesehatan adalah sekolah namun kuantitas jumlah sekolah di desa Arjasa tidak dapat mewakili jumlah penduduk juga. Banyak penduduk desa yang maksimal pendidikannya adalah tingkat SLTP seperti yang terjadi salah satunya dusun Calok. Pendidikan merupakan salah satu alat untuk meningkatkan pola pikir sehingga lebih kreatif dalam menghadapi peluang dan tantangan. Tingkatan pendidikan masyarakat yang rata rata sampai sekoalh SLTP mempengaruhi pola pikir dalam memanfaatkan internet. Ketika provider komunikasi sudah mulai sampai desa penggunaan internet sudah terbesar ketiga dibanding 6 desa di kecamatan Arjasa yaitu sebesar 223 penduduk, pemanfaatan internet hanya sebatas hiburan sehingga tidak dapat merubah atau meningkatkan kesejahteraan penduduk melalui usaha sampingan melalui online. Jabaran tersebut kemudian diidentifikasi akar masalahnya menggunakan 5 whys. 5 whys ini dipilih karena menggambarkan hubungan antara efek negatif yang diberikan dan penyebabnya serta dapat menunjukkan hubungan kausal sebab akibat, dan mampu menggabungkan cara berpikir aksi maupun kondisi. Pada 5 whys setiap masalah terdapat dua penyebab yaitu berupa aksi dan kondisi. Aksi disini adalah penyebab sementara yang membawa kondisi secara bersama sama untuk menimbulkan suatu akibat (action causes) berupa suatu gerakan sedangkan kondisi adalah penyebab yang terdapat sebelum suatu gerakan dilakukan bersifat pasif, tidak semua kondisi patut ditindaklanjuti, oleh karena harus sesuai dengan interest investigator. Gambar 4 adalah diagram 5 whys yang menjelaskan akar masalah dari sebuah efek atau kejadian tanaman kolesom jawa hanya berakhir dipembuangan sampah pada linhkungan desa Arjasa. 


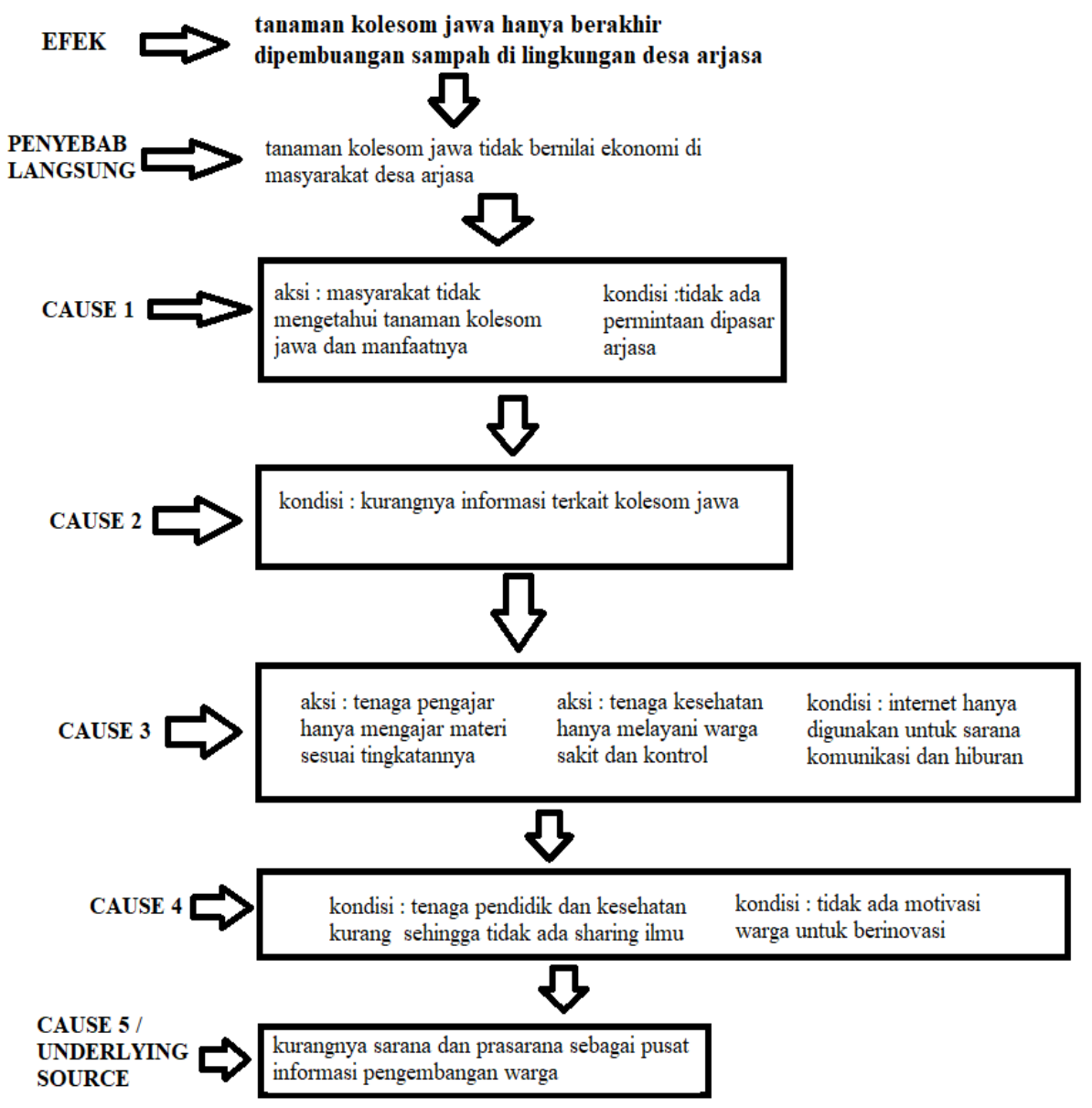

Gambar 4. Five whys diagram

Upaya yang akan dilakukan untuk mencapai tujuan pemanfaatan tumbuhan liar (kolesom) saat musim hujan dengan meningkatkan nilai ekonomi tanaman adalah melalui serangkaian kegiatan yang di kemas dalam bentuk kegiatan pengabdian yaitu dengan metode PRA (Partisipatory Rural Appraisal) berupa penyuluhan dengan kegiatan sosialisasi dan praktek pengenalan tanaman kolesom jawa dan khasiatnya, kemudian dilanjutkan cara budidaya, membuat produk hilir kolesom jawa dan digital marketing sehingga warga dapat menambah penghasilan dari berjualan produk kolesom jawa dengan Metode ini digunakan untuk penyampaian informasi karena telah terbukti mampu meningkatkan peran serta partisipan sehingga meningkatkan keberlanjutan dari program pengabdian (N. I. Ratnaningtyas, dkk. 2019). Budidaya digunakan agar hasil tanaman kolesom didesa Arjasa dapat berkembang baik tidak hanya saat musim hujan sehingga kualitas dan kuantitas yang dihasilkan sesuai kebutuhan pasar dan lingkungan tetap tertata rapi agar terjaga walaupun tanaman liar atau gulma dikembangkan. Ketika budidaya berhasil dilakukan langkah selanjutnya adalah memanfaatkan hasil panen. Kegiatan ini berbasis community untuk mempermudah penyampaian materi dan produksi. Pemanfaatan hasil panen ini menggunakan manajemen produk dan merk untuk menghasilkan varian produk yang akan dipasarkan. Penjualannya berbentuk kolaborasi MTO (make to order) dan MTS (make to stock). Pembentukan komunitas ini bertujuan agar sesama warga yang terlibat dalam kegiatan ini tidak timbul persaingan yang sering dialami persaingan pelaku usaha sejenis. Tim pengabdian dan warga bersama sama melakukan diskusi untuk menentukan varian produk dan merek. Setelah terbentuk beberapa varian produk dan merek maka langkah selanjutnya adalah mengkomersialisasikan produk melalui digital marketing dengan pelatihan terutama penggunaan sosial media dan e-commerce yang sudah tersedia. Pelatihan ini juga diberikan tips dan trik dalam memperkenalkan brand di digital marketing. Trik dan tips yang digunakan 
pada penjualan menggunakan kolaborasi MTO dan MTS. Kegiatan ini membutuhkan rentang waktu yang cukup lama karena keberhasilan budidaya dapat dilihat pada masa panen yaitu 3 sampai enam bulan sejak tanaman itu disemai. Tahun pertama digunakan untuk sosialisasi, pelatihan dan pendampingan budidaya kolesom kepada warga dengan para pakar pertanian tepatnya bidang agronomi yang termasuk dalam tim pengabdian kemudian dilanjutkan dengan sosialisasi pemahaman terkait wirausaha menggunakan digital marketing berbasis komunitas yang dilakukan oleh tim pengabdian yang telah berpengalaman dalam digital marketing berbasis komunitas. Pada tahun kedua dilakukan sosialisasi pelatihan dan pendampingan digital marketing. Sosialisasi, pelatihan dan pendampingan digital marketing ini dilakukan bersama pakar e-commerce yang termasuk dalam tim pengabdian. Pada pelatihan dan pendampingan digital marketing tidak hanya belajar memasarkan produk ke internet namun juga belajar tentang varian produk dan merek sebagai penunjang promosi online dalam memperkenalkan produk melalui pemasaran online.

\section{KESIMPULAN}

1.Identifikasi akar masalah diperoleh dari kegiatan analisis deskripsi kualitatif melalui survey wawancara kemudian dianalisis menggunakan Teknik fishbone untuk memperoleh penyebab terjadinya masalah yang dihadapi. Teknik fishbone ini sebagai arahan kemudian dilanjutkan dengan teknik 5 whys karena dapat menunjukkan hubungan kausal sebab akibat, dan mampu menggabungkan cara berpikir aksi maupun kondisi.

2. Akar masalah yang didapat adalah kurangnya sarana dan prasarana sebagai pusat informasi pengembangan warga.

3. Solusi yang dilakukan adalah dalam bentuk penyuluhan berupa sosialisasi dan praktek terkait dengan pengenalan tanaman dan khasiatnya, kemudian pembuatan varian produk hilir tanaman dan penjualan dengan menggunakan digital marketing. Kegiatan ini dapat dilakukan dalam waktu dua tahun karena hasil budidaya dapat dilihat setelah masa panen tanaman kolesom jawa yang kurang lebih membutuhkan waktu 6 bulan.

\section{UCAPAN TERIMA KASIH}

Ucapan terima kasih kami sampaikan kepada Lembaga Penelitian dan Pengabdian Universitas Jember sebagai penyelenggara pengabdian, warga dan aparatur desa Arjasa, serta mahasiswa mahasiswa fakultas pertanian dan ilmu komputer dan petani desa Arjasa yang telah membantu terselenggaranya pengabdian ini

\section{DAFTAR PUSTAKA}

Badrunasar. A, Santoso. H.B . 2016. Berkhasiat Obat Tumbuhan Liar. ISBN 978-602-6961-150. Balai Penelitian Teknologi Hasil Hutan Bukan Kayu. Mataram.

Natasha, K. dkk. 2019. Optimasi sterilisasi eksplan pada kultur in vitro ginseng jawa (Talium paniculatum). Prosiding Symbion (Symposium on Biology Education). Prodi Pendidikan Biologi, FKIP, Universitas Ahmad Dahlan. 30 Agustus 2019.e-ISSN: 2528-5726.

Koordinator Statistik Kecamatan Arjasa, 2018. kecamatan Arjasa dalam angka 2018. Nomor Publikasi 35096.1825. Katalog BPS 1102001.3509220. Badan Pusat Statistik Kabupaten Jember. Jember 
N. I. Ratnaningtyas, dkk. 2019. Introduksi Pemanfaatan Eceng Gondok Sebagai Pakan Ternak Fermentasi Pada Peternak Kambing Desa Wanadadi Banjaregara. Jurnal Pengabdian Kepada Masyarakat. Volume 25. No. 4. Oktober-Desember 2019. p-ISSN: 0852-2715. eISSN:2502-7220. DOI:https://doi.org/10.24114/jpkm.v25i4.14906

Setiawan, N. Y., Pramono, D., \& Susanto, T. (2018). Analisis dan Perbaikan Proses Bisnis Menggunakan Metode Business Process Improvement (BPI) (Studi Kasus : PT Wonojati Wijoyo). Jurnal Pengembangan Teknologi Informasi dan Ilmu Komputer, 6201-6209. 